\title{
Junctional Bradycardia by ECG Finding
}

National Cancer Institute

\section{Source}

National Cancer Institute. Junctional Bradycardia by ECG Finding. NCI Thesaurus. Code C71074.

An electrocardiographic finding of a junctional rhythm with a heat rate which is abnormally low. (CDISC) 